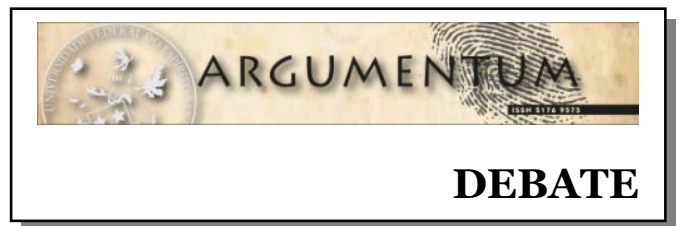

\title{
Segurança e Racismo como pilares sustentadores do Estado Burguês
}

\author{
Security and Racism as supporting pillars of the Bourgeois State
}

\author{
Andrea Pires ROCHA* \\ https://orcid.org/0000-0003-4158-7541
}

\section{Palavras iniciais}

\begin{abstract}
"Eu estava pagando o sapateiro e conversando com um preto que estava lendo um jornal. Ele estava revoltado com um guarda civil que espancou um preto e amarrou numa árvore. O guarda Civil é branco. E há certos brancos que transforma preto em bode expiatório. Quem sabe se guarda civil ignora que já foi extinta a escravidão e ainda estamos no regime da chibata?"

(Carolina Maria de Jesus)
\end{abstract}

\begin{abstract}
Tarolina Maria de Jesus (2014), mulher negra, favelada, "catadora de papel" que, mesmo com nível de escolaridade baixíssimo, ousou, na década de 1950, relatar seu cotidiano em diários, abordando a "questão social", não por elaborá-la teoricamente, mas por demonstrar a materialização das contradições do capitalismo, centradas na exploração, no racismo e no patriarcado ${ }^{1}$, a partir das próprias vivências. E, como "[...] o concreto é concreto porque é a síntese de muitas determinações, isto é, unidade do diverso [...]” (MARX, 1987, p. 16), o fragmento citado na epígrafe ilustra elementos essenciais para compreensão da relação que envolve Questão Social, Violência e Segurança Pública, a partir de reflexões mediadas pelas categorias singularidade, particularidade e universalidade, no campo de uma análise crítica à sociabilidade burguesa e seus desdobramentos.
\end{abstract}

No Estado burguês as relações estruturais estão centradas na propriedade privada, na exploração de mais-valia e no acúmulo de capital, as quais são sustentadas por meio de um conjunto de elementos situados na esfera superestrutural. Neste terreno, a ideologia dominante é capaz de justificar, impor e manter mecanismos de opressão e

\footnotetext{
* Professora. Doutora em Serviço Social. Docente do Departamento de Serviço Social da Universidade Estadual de Londrina. (UEL, Londrina, Brasil). Rodovia Celso Garcia Cid - PR $445 \mathrm{Km} 380$ - Campus Universitário Cx. Postal 10.011, Londrina (PR), CEP 86.057-970. E-mail: drea_rocha@yahoo.com.br. ${ }^{1}$ Entendemos o Patriarcado como um dos mecanismos de opressão do Capitalismo, no entanto, neste debate iremos nos ater a simbiose entre questão de classe e questão racial.
} S Atribuição 4.0 Internacional (https://creativecommons.org/licenses/by/4.o/deed.pt_BR), que permite copiar e redistribuir o material em qualquer suporte ou formato, bem como adaptar, transformar e criar a partir deste material para qualquer fim, mesmo que comercial. O licenciante não pode revogar estes direitos desde que você respeite os termos da licença. 
desigualdade, em nome da manutenção do Capitalismo. Por isso, a intenção deste texto é provocar algumas reflexões acerca dos fundamentos do Estado capitalista como historicamente penal, subsidiado pelo princípio burguês da segurança e tendo o racismo como um de seus pilares estruturantes.

Este modelo de sociabilidade dedica-se a criminalizar e a prender corpos pobres e não brancos que lotam as prisões no mundo, culpabilizando-os pelas contradições estruturais que os atingem. A funcionalidade das instituições prisionais como instrumentos de controle racistas e seletivos, não é um fenômeno recente no Brasil a medida em que a construção de legislações penais voltadas ao controle de pobres, principalmente de negros, compõe historicamente a delineação das relações sociais brasileiras.

É estarrecedor ver onde chegamos. No neoliberalismo, o controle das expressões da questão social pela via da penalização cresceu de forma exponencial. Segundo informações oficiais do governo publicizados no INFOPEN ${ }^{2}$ (BRASIL, 2020), no ano 2000 a população do sistema prisional era de 232.755 pessoas, que triplicou em dez anos, chegando em 2019 ao alarmante índice de 755.274. Dados mostram que no período de junho a dezembro de 2019 o Brasil privou de liberdade 748.009 pessoas, dessas $29,75 \%$ estavam prisão provisória, 48,47\% cumprindo regime fechado, $17,84 \%$ em semiaberto, 3,36\% em regime aberto, 0,55\% em Medidas de Segurança e 250 pessoas em tratamento ambulatorial.

É evidente que o Brasil escolheu o Estado penal em detrimento do Estado social. Vivenciamos a atual crise do capital agravada por uma crise de saúde pública sem fronteiras. Havia uma retórica afirmando que a pandemia do Coronavirus era democrática por atingir igualmente ricos e pobres. Mas a "democracia" da doença COVID-19 mata mais pobres e negros. Os efeitos nefastos do desemprego estrutural, da miséria, da fome, somados ao desmonte da saúde pública e da ausência de saneamento básico, se mostram com mais crueldade em tempos de COVID-19. As mortes a contagotas de todos os dias são substituídas por imagens, quase surreais, de corpos em caminhões frigoríficos.

Enquanto escrevíamos a primeira versão deste texto a doença já havia matado mais de 14.0oo brasileiros e, ao concluí-lo, nos aproximamos de 180 mil mortes. Na esteira da pandemia, o governo fascista de Jair Bolsonaro, liberal na economia e conservador nos valores, impõe o recrudescimento do projeto genocida de pretos, pobres e indígenas, residentes em territórios sociais vulneráveis ou segregados em prisões. Torna-se impossível qualquer tentativa de se camuflar as mazelas. O capitalismo está nu.

\section{Lugar da Segurança no Estado burguês}

[...] E, quando permitem que fujamos à disciplina, tombamos nos braços da Deusa do Século, a Polícia. Polícia quando se pensa. Polícia, quando se fala.

\footnotetext{
2 Outros estudos apontam números superiores, porém optamos por usar os dados oficiais do DEPEN, para impedir que alguém tente refutá-los.
} 
Polícia, quando se anda a pé, a cavalo ou de carro. [...]. Que o diabo mate os gigantes e os dragões!

(ENGELS, A Terra Natal de Siegfried, 1840).

Sob a égide da ideologia política e econômica neoliberal, desmonta-se todo sistema de proteção social conquistado historicamente, em nome do fortalecimento da economia. Evidente que dessa lógica se agravam os impactos das expressões da questão social, as quais, por sua vez, serão administradas por medidas de Segurança Pública, cunhadas no racismo e mediadas pela seletividade penal atingindo os negros em específico e pobres no geral.

Garland (2014) explica que em oposição aos lemas da socialdemocracia, no neoliberalismo há o fortalecimento do apelo moralizante direcionado aos pobres e comunidade marginalizadas, que além de serem atingidos pelo desmonte dos direitos sociais, tornam-se foco direto do controle pela via penal. Wacquant (2001) define o Estado penal como uma resposta "[...] às desordens suscitadas pela desregulamentação da economia, pela dessocialização do trabalho assalariado e pela pauperização relativa e absoluta" [...] (WACQUANT, 2001, p. 7), que se dá a partir da ampliação da “[...] intervenção do aparelho policial e judiciário, equivale a (r)estabelecer uma verdadeira ditadura sobre os pobres" (WACQUANT, 2001, p. 7). O autor recorrentemente faz uma analogia usando a expressão Leviatã ao se referir as características opressivas do neoliberalismo. Aponta que o controle dos pobres se materializa de diferentes formas, especialmente pela via da socialização, da medicalização e da penalização, esta última serve como:

[...] técnica para a invisibilização dor problemas sociais que o Estado, enquanto alavanca burocrática da vontade coletiva, não pode ou não se preocupa mais em tratar de forma profunda, e a prisão serve de lata de lixo judiciária em que são lançados os dejetos humanos da sociedade de mercado (WACQUANT, 2013, p. 21).

Desresponsabilizado da garantia dos direitos para a classe trabalhadora, o Estado neoliberal, utiliza-se do problema da chamada violência urbana, criada por ele mesmo, para aplicar medidas de controle e repressão. Angela Davis (2018) aponta que na análise de abolicionistas "[...] a construção de prisões e a eventual necessidade de ocupar essas novas estruturas com corpos humanos foram guiadas por ideologias racistas e pela busca desenfreada de lucro" (DAVIS, 2018, p. 92). Nutre-se, desta forma, o encarceramento em massa, que segundo Alexander (2017), "[...] opera como um sistema firmemente amarrado de leis, políticas, costumes e instituições que operam coletivamente para assegurar a condição subordinada de um grupo definido em grande medida pela raça" (ALEXANDER, 2017, p. 50-51).

Também vale a pena destacarmos que para Giorgi (2013), o encarceramento de agora não tem mais o objetivo de disciplinar para o trabalho, mas o foco é a segregação total, administrando a população considerada excedente que, para o capital, não possui serventia nem mesmo para engrossar as filas do exército industrial de reserva. O Brasil adotou esse mecanismo e a tragédia se mostra no fato de que de 1990 a 2016, o número de pessoas privadas de liberdade no país cresceu 756\% (BRASIL, 2017). No entanto, o

Argum., Vitória, v. 12, n. 3, p. 10-25, set./dez. 2020. | ISSN 2176-9575 
neoliberalismo faz recrudescer os pilares liberais que delinearam o Estado burguês nos séculos XVII e XVIII. Ou seja, atualmente o braço coercitivo se mostra de forma nua e crua, para a manutenção da sociabilidade burguesa. Neste sentido, vale a pena lembrarmos que no contexto do Iluminismo, Hobbes defende um formato de Estado a partir de um Absolutismo civil - chamado de Leviatã ${ }^{3}$ - que deveria ser aceito pelos "homens", por ser "[...] capaz de defendê-los das invasões dos estrangeiros e das injúrias uns dos outros, garantindo-lhes assim uma segurança suficiente para que, mediante seu próprio labor e graças aos frutos da terra” (HOBBES, 2003, p. 61).

Pouco tempo depois, dar-se-á início à construção do pensamento Liberal que se centrava na contraposição ao Absolutismo. Em linhas gerais, o precursor, John Locke $(1998)^{4}$ desconstrói o entendimento hobbesiano de que os homens são naturalmente maus, definindo-os como naturalmente livres, o que os coloca em condição de igualdade, que na prática se refere ao individualismo e a meritocracia. A partir deste raciocínio, a sociedade não necessitaria do poder do Estado, pois os homens são plenamente capazes de regular suas ações, considerando também que a razão os permite transformar a natureza e o fruto do trabalho irá garantir o direito à propriedade, que até então era privilégio da igreja e da monarquia. Por tudo isso, o pensamento Liberal rompe com o Absolutismo, não com o Leviatã hobbesiano, quando se trata da manutenção da propriedade privada.

O pensamento de Locke, somado a outros liberais, impulsiona as chamadas Revoluções burguesas, que consolidaram a ascensão da burguesia como classe detentora das rédeas do modo de produção capitalista. O Estado torna-se burguês reconfigurando-se como "[...] produto e a manifestação do antagonismo inconciliável das classes" (LENIN, 2007, p. 25). Portanto, “[...] é um órgão de dominação de classe, um órgão de submissão de uma classe por outra; é a criação de uma 'ordem' que legalize e consolide essa submissão, amortecendo a colisão de classes” (MARX apud LENIN, 2007, p. 25).

Neste terreno que também se dá a concepção burguesa dos Direitos Humanos ${ }^{5}$ assentada nos princípios liberdade, igualdade, propriedade e segurança. A declaração Francesa dos Direitos do Homem e do Cidadão, de 1789, destaca em seu preâmbulo que "[...] a finalidade de toda associação política é a conservação dos direitos naturais e imprescritíveis do homem. Esses direitos são a liberdade, a propriedade, a segurança e a resistência à opressão". A igualdade civil se centrava no homem, branco e proprietário, excluindo os pobres, as mulheres e os negros - que na época mantiveramse escravizados. Liberdade e propriedade caminham de mãos dadas e são garantidas pela segurança.

\footnotetext{
3 Thomas Hobbes, publica em 1651 a obra “O Leviatã".

4 Publicada em 1689.

5 É importante apontarmos que concordamos com a análise de Trindade (2011) de que, mesmo com natureza burguesa, os Direitos Humanos passam, ao longo da história, por mudanças importantes, as quais se deram sob a influência de pautas classistas, feministas, de movimentos de luta por igualdade racial, e muitos outros. É claro que essas mudanças permanecem na esfera reformista de aspectos do Estado burguês e na maioria das vezes se referem a positivação de direitos que permanecem apenas na esfera formal, mesmo assim entendemos que se tornam instrumentos para luta. No entanto, não podemos deixar de destacar que a luta dos negros e dos indígenas no contexto escravocrata e colonial antecederam a concepção burguesa e sempre se mostraram como reinvindicações por Direitos Humanos.
} 
Atualmente, podemos visualizar que a segurança se concretiza como proteção da própria ordem do capital materializada duas esferas: segurança econômica concretizada na proteção aos grandes capitais; e segurança pública, para proteger propriedade e proprietários. Existe como instrumento do Estado burguês a partir de uma lógica perversa que, em nome da propriedade e liberdade de alguns se constrói aparatos repressivos contra outros, atingindo as pessoas de forma diferente, dependendo das condições de classe, étnico-raciais e gênero.

Para tal, há o estabelecimento de um conjunto de relações jurídicas, que estão na esfera superestrutural, salvaguardando e protegendo a estrutura. Rusche e Kirchheimer (2004) apontam que "[...] todo sistema de produção tende a descobrir formas punitivas que correspondem as suas relações de produção [...]" (RUSCHE; KIRCHHEIMER, 2004, p. 19), que são determinadas por forças sociais, situadas, especialmente nas esferas da economia e fiscais. Enfatizam que as prisões, no modelo que as conhecemos hoje, foram criadas no contexto do capitalismo para controlar o proletariado.

E a realidade atual nos levam a concordar que "[...] as demandas por ferocidade penal, a seletividade da clientela do sistema penal são permanências históricas” (MALAGUTI BATISTA, 2014, p. 135). Portanto, o fato do sistema punitivo representar o interesse da classe dominante o faz imensamente seletivo apresentando-se como “[...] um subsistema funcional da produção material e ideológica (legitimação) do sistema social global, isto é, das relações de poder e de propriedade existentes[...]” (BARATTA, 1987, p. 623). $\mathrm{O}$ funcionamento desta lógica, dependerá também de aparatos concretos que os executem, por isso, Engels ao falar do aspecto repressivo do Estado, refere que é formado pela polícia, mas:

[...] não só de homens armados como, ainda, de acessórios materiais, os cárceres e as instituições coercitivas de todo gênero[...] se fortalece na medida em que exacerbam os antagonismos de classe dentro do Estado e na medida em que os Estados contíguos crescem e aumentam de população. [...] (ENGELS, 1984, p. 192)

Quanto mais antagonismos do capitalismo, mais repressão, ou seja, historicamente os instrumentos repressivos, que culminam no encarceramento de pessoas, carregam consigo um poder político no controle da luta de classes. A materialidade dessas reflexões também se mostram no fato da Constituição Federal brasileira de 1988 definir em seu Art. 144 que, "[...] a Segurança Pública, dever do Estado, direito e responsabilidade de todos, é exercida para a preservação da ordem pública e da incolumidade das pessoas e do patrimônio [...]" (BRASIL, 1988, não paginado) executada por meio de órgãos policiais.

Essa concepção tem dado certo, pois os dados do DEPEN (BRASIL, 2020) nos mostram que os delitos que mais encarceram no Brasil são os crimes contra patrimônio, 50,96\%; questão das drogas proíbidas, $20,28 \%$ e contra a pessoa $17,36 \%$. Portanto, os impactos do Estado neoliberal de cunho penal, se referem a manutenção de um modelo de sociedade cuja a Segurança é instrumento repressivo racista amparada na seletividade penal, mostrando-se como opressiva e violenta, jamais como proteção de todos. 


\title{
3 Racismo, o pilar burguês geralmente negado
}

\author{
A voz da minha bisavó \\ Ecoou criança \\ nos porões do navio. \\ ecoou lamentos \\ de uma infância perdida. \\ [....] \\ (Conceição Evaristo)
}

A escravidão escancara que racismo e capitalismo sempre estiveram entrelaçados. Evidencia o quanto a gênese dos Direitos Humanos é limitada, e a prova irrefutável desta contradição se mostra no processo da revolução no Haiti ${ }^{6}$, que obrigou a República francesa mostrar resistência mediante luta dos haitianos pelo fim colonialismo e da escravidão (LOSURDO, 2006; JAMES, 2010). Refletiremos quanto os princípios basilares do pensamento Liberal se unem ao racismo, dando sustentação ideológica e material ao Estado burguês, que sempre se valerá da segurança para administrar essas relações.

É importante entendermos que, segundo Munanga (2003), os pensadores do Iluminismo ${ }^{7}$ ao redesenharem a sociedade, também passam a explicar o racismo a partir da racionalidade que cimentará o Racialismo, tratando seres humanos diferentes do padrão branco europeu como inferiores, perigosos e selvagens. As grandes descobertas atribuíam imagens degradantes aos negros residentes no continente africano "[...] designando-lhes o lugar mais baixo na escala humana, ela preparava de certa maneira os espíritos para o gigantesco tráfico transatlântico dos quatro séculos seguintes" (M’BOKOLO, 2008 p. 242).

Williams (2012), nos mostra que em concomitância ao processo de consolidação do modo de produção capitalista acontecia a escravidão, possibilitando que a exploração de recursos naturais dos países colonizados acontecesse a partir da espoliação total do trabalho dos negros escravizados. Desta forma, o racismo é um importante pilar para justificar o tráfico negreiro e o colonialismo em suas duas fases, na primeira vinculada ao mercantilismo, na segunda ao imperialismo, aprofundando as diferentes formas de exploração que o modo de produção capitalista empreende.

Magali Almeida (2014), afirma que só podemos identificar a questão social e suas expressões a partir das “[...] dimensões ocultadas ou invisibilizadas pela lente do imperialismo e do colonialismo, nas quais são privilegiadas as relações sociais hierárquicas estruturadas pelo racismo patriarcal e pela dominação de classe" (ALMEIDA, 2014, p. 146). Neste sentido, defendemos que só podemos entender a questão social como resultado da relação entre questão racial, questão de classe e questão de gênero, delineadas pelos mecanismos de opressão racismo, exploração e

\footnotetext{
${ }^{6}$ A luta pela independência da então Colônia de São Domingos, a revolução do Haiti, que teve seu início nos primeiros anos Pós Revolução Francesa e, principalmente, após a Declaração dos Direitos do Homem e do Cidadão (JAMES, 2010).

7 Munanga destaca o francês François Bernier, como o precursor da modernidade a empregar o termo raça para classificar a diversidade humana em grupos fisicamente contrastados. Sugerimos também a leitura do texto do pesquisador Somet (2016), que ao abordar racismo e filosofia.
} 
patriarcado, os quais se retroalimentam em nome da manutenção da ordem societária capitalista. Gonçalves (2018) problematiza que se é consenso que a questão social é produzida pelo capitalismo é impossível que desconsideremos que "[...] a questão racial e seu mais grave subproduto, o racismo, fazem parte das relações que impulsionam e dinamizam a sociedade burguesa" (GONÇALVES, 2018, p. 520).

O racismo, portanto, é estrutural, a medida em que sua reprodução sistêmica se mostra "[...] na organização política, econômica e jurídica [...]" (ALMEIDA, 2018, p. 38), o que nos leva a entendê-lo como um pilar do Estado burguês ao determinar a manutenção de desigualdades em diferentes esferas, fazendo com que a população negra ocupe os piores lugares nas franjas do exército de reserva e seja atingida por uma miríade de violações de direitos, pois, "[...] as refrações da questão social que incidem sobre esta população têm suas raízes na escravidão e foram reconfiguradas no trabalho livre" (ALMEIDA, 2014, p. 142). Obstante a isso, refutamos qualquer análise que retire a questão racial da composição do modo de produção capitalista e de sua questão social, seja ela decorrente de teorias diretamente racistas, cunhadas no negacionismo do "mito da democracia racial" centradas radicalmente na categoria classe social. É impossível mantermos a invisibilidade das tragédias que atingem uma parcela da classe trabalhadora brasileira, não somente por ser pobre, mas por ser negra.

Lélia Gonzáles (1984) desenvolve uma síntese sobre a determinação de lugares naturalizados e totalmente distintos para brancos e negros - dominadores e dominados -, apontando que isso se dá desde o contexto colonial. Enfatiza que os lugares naturalizados para as pessoas brancas pertencentes às classes dominantes correspondem a “[...] moradias saudáveis[...] protegidas por diferentes formas de policiamento que vão desde os feitores, capitães de mato, capangas, etc, até à polícia formalmente constituída [...]" (GONZÁLES, 1984 p. 232). Por outro lado, o lugar imposto a população negra? ,

[...] é o oposto, evidentemente: da senzala às favelas, cortiços, invasões, alagados e conjuntos 'habitacionais' dos dias de hoje, o critério tem sido simetricamente o mesmo: a divisão racial do espaço [...], aqui também se tem a presença policial; só que não é para proteger, mas para reprimir, violentar e amedrontar. É por aí que se entende porque o outro lugar natural do negro sejam as prisões. A sistemática repressão policial, dado o seu caráter racista, tem por objetivo próximo a instauração da submissão (GONZÁLES, 1984, p. 232).

Revela que no bojo das determinações provocadas pelo racismo estrutural, os aparelhos repressivos do Estado estão presentes em ambos os lugares, para alguns como proteção e para outros repressão, naturalizando-se também as prisões como lugar para as pessoas negras. Portanto, quando tratamos da segurança pública, observamos que a seletividade penal ancorada na construção ideológica do negro como perigoso ainda persiste na delineação ou aplicação de legislações, fazendo com que,

\footnotetext{
${ }^{8}$ Cunhado essencialmente nas teses de Gilberto Freyre e Raimundo Nina Rodrigues.

9 É claro que existem pessoas brancas em territórios pobres, também submetidas a diferentes formas de opressão, no entanto, sobre essas, o racismo não se aplica.
} 
nos dias de hoje, 6o\% das pessoas presas no Brasil seja formada por negros, somandose pretos e pardos. Baratta (1999) enfatiza que a seletividade penal é delineada pelas categorias de classe, gênero e raça/etnia, neste sentido, o sistema de justiça criminal “[...] a um só tempo, reflete a realidade social e concorre para sua reprodução. Esta dependência recíproca entre o sistema punitivo e a estrutura social constitui uma relação complexa" (BARATTA, 1999, p. 42). Por isso, abordaremos em linhas gerais algumas nuances da gênese do sistema penal no processo de configuração do Estado burguês brasileiro, refletindo-o no contexto da primeira República, como um mecanismo de controle e criminalização dos negros e dos pobres.

\title{
4Da escravidão ao encarceramento em massa: a particularidade brasileira
}

\author{
"O escravo que mata o senhor, seja em que \\ circunstância for, mata sempre em legítima defesa”. \\ (Luiz Gama apud POMPEIA, 2015)
}

A escravidão é uma categoria social, cuja a característica essencial do "[...] ser escravo reside na condição de propriedade de outro ser humano [...]” (GORENDER, 2016, p. 89) tratado juridicamente na esfera das mercadorias. No entanto, a escravidão é mediada por situações em que os negros escravizados, na tensão da condição que lhe foi imposta, demonstram sinais de resistência, pois "[...] o primeiro ato humano do escravo é o crime, desde o atentando contra o senhor à fuga do cativeiro" (GORENDER, 2016, p. 94). Assim, o negro, primeiro visto como "o outro" - inferior por suas características físicas e culturais, passível de escravização para o trabalho forçado, comparado a animais de uso doméstico -, passa a ser estigmatizado como o criminoso capaz de reagir a condição que lhe foi imposta. Contudo, "[...] em contrapartida, ao reconhecer a responsabilidade penal dos escravos, a sociedade escravista os reconhecia como homens: além de incluí-los no direito das coisas, submetia-os à legislação penal" (GORENDER, 2016, p. 94).

Por isso, a questão da segurança burguesa se manifesta de duas formas, primeiro protegendo a essencialidade da coisificação, garantindo ao proprietário poder sobre a propriedade, neste caso, seres humanos escravizados. E, em segundo plano, garantindo segurança ao proprietário, em resposta a qualquer ato de resistência das pessoas escravizadas. Elementos esses mediados pelo racismo, que estabelecem a escravidão e a criminalização das pessoas negras.

Lembremos que enquanto a economia política mundial estava aderindo ao Liberalismo clássico e as prisões modernas passam a se consolidar, no Brasil colonial persistiam práticas de tortura e suplícios. Gorender (2016) ressalta que no contexto do Escravismo Colonial, o Estado assume o "direito de vida e morte" a partir de julgamentos ${ }^{10}$ rigorosos que poderiam levar a pena de morte negros que entraram em conflito com seus proprietários ou envolvidos em lutas de resistência. Moura (1989) aponta que a estratificação social era determinada por duas classes fundamentais, senhores e escravos, que se chocavam e delineavam os níveis de conflitos. No interior dessa

\footnotetext{
${ }^{10}$ Até o processo de Independência, a legislação que disciplinava se referia as "Ordenações Felipinas" e segundo Ferreira (2017) não dispunham de tribunais específicos para o julgamento das situações que envolviam escravos.
} 
contradição, os negros passam a criar formas de resistência contra a condição de opressão, recorrendo-se a guerrilhas, insurreições urbanas e quilombos ${ }^{11}$.

Malagutti Batista (2014) ressalta que a Constituição de 1824 "[...] produz algumas rupturas, ma non tropo, que fazem parte do universo liberal no conjunto das ideias fora do lugar da modernização à brasileira [...]" (MALAGUTTI BATISTA, 2014, p. 135), algumas garantias individuais, sem perder de vista o direito à propriedade, assegurando-se desta forma a manutenção da escravidão e a forte repressão sobre as insurreições negras ${ }^{12}$. Enfatiza que assim carrega-se "[...] para o futuro as marcas de um sistema penal público/privado, com o poder punitivo incidindo sobre os corpos negros/índios/pobres [...]" (MALAGUTTI BATISTA, 2014, p. 139), que assentado em concepções jurídicas herdadas da violência colonial, persiste em diferentes contextos sócio-políticos do país.

Neste contexto que o Código Criminal do Império do Brasil de 1830 (BRASIL, 1830) foi promulgado. Analisamos o documento original e vimos que os castigos corporais contra os escravos são legitimados e eram priorizados em detrimento a prisão, satisfazendo as necessidades da sociedade escravocrata, pois mais útil era castigar e ainda ter a força de trabalho, do que tê-los presos e improdutivos durante o período recluso. Essa lei também versa por determinar a mendicância e a vadiagem como crimes, que segundo Flauzina (2008, p. 70), “[...] em última instância, é a criminalização da liberdade: aos negros não é facultado o exercício de uma liberdade sem amarras da vigilância" (FLAUZINA, 2008, p. 70). Ampliou-se o número de pessoas submetidas ao sistema penal, levando, segundo Chazkel (2017), em 1834, a inauguração da primeira Casa de Correção do Império e em 1856 da casa de Casa de Detenção, ambas no Rio de Janeiro.

Somada a resistência negra, no final do século XIX, o país vivenciava diferentes efervescências políticas, materializadas especialmente em movimentos abolicionistas de cunho liberal, que envolvia, inclusive abolicionistas negros, à exemplo do Luiz Gama, da epígrafe da seção. No entanto, Florestan Fernandes (2006) ao contextualizar o processo que culminou no fim da escravidão do Brasil enfatiza que o impulso foi a abertura para a competição, combatendo-se, não a escravidão em si mesma, mas enxergando-a como a manutenção do atraso em uma sociedade que já havia extinguido o status colonial e "[...] pretendia organizar-se como nação e procurava, por todos os meios, expandir internamente a economia de mercado" (FERNANDES, 2006, p. 36).

Buscava-se no Brasil a completude dos princípios burgueses liberdade, igualdade, propriedade e segurança, mantendo-se o racismo como pilar para construção do novo modelo social que surgiria. Em tese, em 1888, a grande maioria da população negra já havia se libertado, por meio da resistência coletiva ou comprando a própria alforria. Mas, a abolição formalizou esse processo, abrangendo aqueles que ainda estavam sobre

\footnotetext{
${ }^{11}$ Os quilombos podem ser vistos como "[...] nódulos de resistência permanente ao sistema escravista. [...] Era o exemplo da democracia racial de que tanto se fala, mas que nunca existiu no Brasil, fora das unidades quilombolas" (MOURA, 1989, p. 37).

${ }^{12}$ Segundo Pirola (2012), a criação da lei de 10 de Junho de 1835, voltada a repressão de movimentos dos negros em resistência a escravidão, facilitando a aplicação da pena de morte para os rebeldes.
}

Argum., Vitória, v. 12, n. 3, p. 10-25, set./dez. 2020. | ISSN 2176-9575 
a égide da escravidão. No entanto, não havia nenhum interesse de abalar o poder das classes dominantes. A abolição brasileira torna-se formal, impedindo uma real igualdade de direitos, transformando "[...] o antiescravismo e abolicionismo numa revolução social dos 'brancos' e para os 'brancos' [...]” (FERNANDES, 2006, p. 36), impedindo a construção de qualquer nível de política reparatória para as populações indígenas e negras que foram expropriadas do direito sobre o próprio corpo.

Abdias do Nascimento (2016) analisa essa conjuntura sob a perspectiva do genocídio do negro no Brasil, que se deu por meio de duas estratégias fundamentais: branqueamento da raça e o branqueamento da cultura. Um processo de miscigenação ${ }^{13}$ imposto, muitas vezes a partir da exploração sexual da mulher negra, que buscava eliminar a população negra "purificando" seus corpos e mentes. A segunda estratégia se sustenta na primeira, amarrada ao embranquecimento da cultura africana e tudo o que diz respeito a ela.

Flauzina (2008) ressalta que já nos primeiros anos da República, o coronelismo continuou a ditar as regras no campo, optando por empregar trabalhadores imigrantes brancos ao mesmo tempo em que se agravava a exploração dos negros libertos. Nas regiões urbanas, agrava-se o controle e a criminalização da pobreza por meio da perseguição aos vadios construindo-se uma ideologia que se assentava na "[...] cisão entre uma brancura produtiva e uma negritude ociosa e indolente ia ganhando espaço no imaginário, atingindo necessariamente as práticas punitivas" (FLAUZINA, 2008, p. $81)$.

Nesta perspectiva, o Código Penal de 1890 torna-se importante instrumento de seletividade penal assentada no racismo. O principal destaque está no fato de que somado as categorias criminais mendicância e vadiagem, houve a criação da categoria criminal capoeira, legitimando de maneira direta o racismo que já atingia a população negra brasileira. Visualizamos que a criminalização do Candomblé e outras práticas culturais vinculadas a cultura afro-brasileira se mostram nessa legislação.

A criminalização dos negros e dos pobres torna-se incontestável na legislação criminal do Brasil republicano. Buscamos dados sobre a realidade das prisões nos primeiros anos do século XX, e os dados no site do IBGE, referentes às prisões em 1907, apontam que de um total de 3.613 pessoas presas, 65\% era formada por "negros e mestiços"14 e $35 \%$ por brancos. Mais de cem anos se passaram e o perfil da população submetida ao Estado penal é a mesma, isso não pode ser desconsiderado. A diferença é que agora são mais de 700 mil pessoas submetidas a mesma lógica de sistema racista, seletivo e opressivo.

O Código Criminal da República de 1890 só foi substituído pelo Código Penal de 1940, que ao analisarmos não apresenta elementos que criminalizam diretamente as pessoas negras como na legislação anterior. No entanto, nossa análise nos leva a afirmar que, com a cristalização da imagem do negro como inferior, perigoso, vadio e preguiçoso,

\footnotetext{
${ }_{13}$ Mestiçagem purificaria corpos e mentes negras, tornando-as mais brancas e próximas do ideal. Teses de Raimundo Nina Rodrigues caminham por essa leitura.

${ }^{14}$ Conforme nomenclatura da época
} 
seria desnecessária alguma menção direta. De qualquer forma, vale destacar que a Lei de Contravenções Penais de 1941, apresenta até os dias de hoje a vadiagem como uma contravenção, e a mendicância foi suprimida apenas no ano de 2009.

Além disso, no terreno do debate acerca da criminalização de pretos e pobres, não poderíamos deixar de mencionar, que a ideologia proibicionista concretizada na guerra às drogas, também desenvolve essencial papel no controle desses grupos sociais ${ }^{15}$. Alexander (2017) demonstra o quanto a guerra às drogas é instrumento de controle e justificativa para o encarceramento em massa. Esse elemento também é observado no Brasil, que historicamente aderiu à política proibicionista e à retórica da guerra às drogas, alcançado níveis de prisões extremas pelo delito de tráfico de drogas.

Temos, inclusive, tecido algumas reflexões acerca do juvenicídio brasileiro (ROCHA, 2018; 2020), que tem no genocídio da juventude negra e pobre o ápice de sua materialidade, mas que também se mostra como resultado da vinculação do racismo, da guerra às drogas e do encarceramento em massa. Enfim, não é à toa que jovens, negros e pobres, presos por delitos contra a propriedade - furto e roubo - e por tráfico de drogas, correspondem à grande maioria da população prisional brasileira.

\section{Algumas considerações}

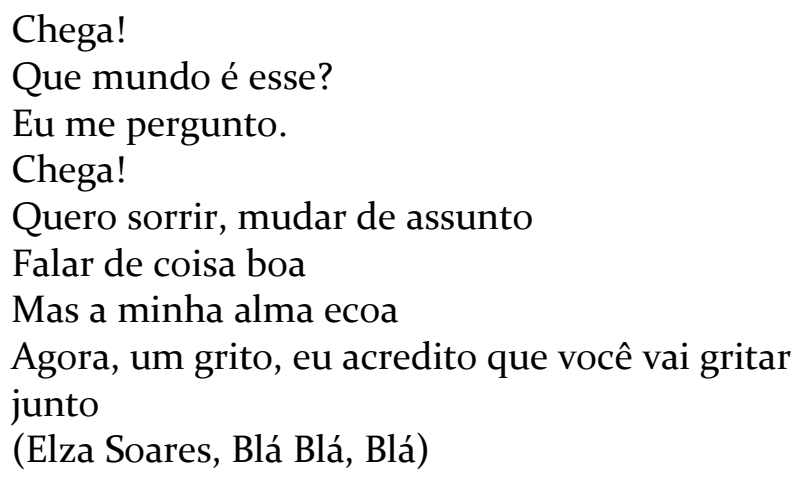

Ideologicamente, o Estado burguês se constrói a partir do pensamento Liberal, centrado nos princípios: liberdade e igualdade para alguns; propriedade como valor central e determinante para a cidadania; segurança como instrumento de proteção da liberdade formal e da propriedade. Este Estado também tem o racismo como um de seus pilares, a medida em que subsidiou o escravismo, o colonialismo e ainda nutre as condições precárias de vida da população negra. Sendo assim, a questão social é resultado da vinculação entre questão de classe, questão étnico-racial e questão de gênero, as quais se retroalimentam em nome da manutenção da sociabilidade burguesa.

Em meio dessa lógica, a Segurança sustenta o modo de produção capitalista em suas diferentes fases, pois o discurso ideologizado se assenta na necessidade de proteção das

15 Sobre esse debate sugerimos: BOITEUX, (2006); D’ELIA FILHO, (2015); ROCHA (2012; 2018; 2020); FERRUGEM (2019); BORGES (2018); VALOIS, (2017), LIMA (2009); FEFFERMAN (2006); RODRIGUES (2004); DELMANTO (2012); PASSETTI (1991).

Argum., Vitória, v. 12, n. 3, p. 10-25, set./dez. 2020. | ISSN 2176-9575 
pessoas, quando na verdade, se volta em favor da propriedade e dos proprietários, impedindo qualquer movimento que possa colocar o capitalismo em risco. E mesmo considerando as particularidades da consolidação das relações sociais brasileiras, é essencial considerarmos que esses elementos opressivos se mostram desde o colonialismo e persistem ao longo da história.

Assim se constrói a política pública de Segurança, cunhada no racismo, mediada pela seletividade penal, administrada pelas instituições policiais e concretizada no encarceramento em massa de negros e pobres. Mediante a essa constatação, o que fazer? Como parte da academia, defendemos que a universidade deve assumir um lugar contra-hegemônico, aquilombando-se, como fala a poesia de Conceição Evaristo, e unindo-se a movimentos que se opõem ao Racismo, ao Patriarcado, ao Proibicionismo, ao Fascismo, os quais além de denunciar o quanto a humanidade está em risco - enquanto se mantiver a lógica do capital-, tentam superá-la.

\section{Referências}

ALEXANDER, Michelle. A nova segregação: racismo e encarceramento em massa. Tradução de Pedro Davoglio. São Paulo: Boitempo, 2017.

ALMEIDA, Magali da Silva. Desumanização da população negra: genocídio como princípio tácito do capitalismo. Em Pauta, Rio de Janeiro, n. 34, v. 12, p. 131- 154, jul./dez. 2014.

ALMEIDA, Silvio. O que é racismo estrutural? Belo Horizonte: Letramento; Justificando, 2018. (Série Feminismos Plurais. Coord. Djamila Ribeiro).

BARATTA, Alessando. Princípios do Direito Penal Mínimo. Trad Francisco Bissoli Filho. Teoria e Pratica em Las Ciencias Penales, ano 10, n. 87, p. 623-650, 1987.

BARATTA, Alessandro. O paradigma do gênero: da questão criminal à questão humana. In: CAMPOS, Carmen Hein (org). Criminologia e Feminismo. Porto Alegre: Editora Sulina, 1999.

BOITEUX, Luciana. A nova lei antidrogas e o aumento da pena do delito de tráfico de entorpecentes. Boletim IBCCrim, São Paulo, ano 14, n. 167, p. 8-9, out. 2006.

BORGES, Juliana. O que é: encarceramento em massa? Belo Horizonte: Letramento; Justificando, 2018.

BRASIL. [Constituição de 1988]. Constituição da República federativa do Brasil de 1988. Brasília (DF): Senado Federal; Centro Gráfico, 1998. Disponível em: http://www.planalto.gov.br/ccivil 03/constituicao/constituicao.htm. Acesso em: 10 de abr. 2013.

BRASIL. Lei de 16 de dezembro de 1830. Manda executar o Codigo Criminal. Rio de Janeiro, 8 jan. 1831. Disponível em: 
http://www.planalto.gov.br/ccivil o3/leis/lim/lim-16-12-183o.htm. Acesso em: 5 maio 2018.

BRASIL. Ministério da Justiça e Segurança Pública. Departamento Penitenciário.

Levantamento Nacional de Informações Penitenciárias: 2020. Brasília (DF), 2020.

BRASIL. Ministério da Justiça e Segurança Pública. Departamento Penitenciário.

Levantamento Nacional de Informações Penitenciárias: Junho de 2016. Brasília

(DF), 2017. Disponível em: https://www.justica.gov.br/news/ha-726-712-pessoas-

presas-no-brasil/relatorio 2016 junho.pdf. Acesso em: 20 nov. 2017.

CHAZKEL, Amy. Uma perigosíssima lição: a Casa de Detenção do Rio de Janeiro na Primeira República. In: MAIA, Clarissa Nunes (org). Historia das Prisões no Brasil. vol 2. Rio de Janeiro: Anfiteatro, 2017.

D’ELIA FILHO, Orlando Zaccone. Indignos de vida: a forma jurídica da política de extermínio de inimigos na cidade do Rio de Janeiro. Rio de Janeiro: Revan, 2015.

DAVIS, Angela. Estarão as prisões obsoletas? Tradução de Marina Vargas. Rio de Janeiro: Difel, 2018.

DELMANTO, Júlio. Imperialismo e proibicionismo: raízes e interesses da proibição das drogas e da suposta guerra ao tráfico. Salvador: Neip, 2010. Disponível em: https://neip.info/novo/wp-content/uploads/2015/o4/imperialismo-e-proibicionismojlio-delmanto.pdf. Acesso em: 15 mar. 2012.

ENGELS, Frederick. A Origem da Família, da Propriedade Privada e do Estado. Rio de Janeiro: Civilização Brasileira, 1984.

EVARISTO, Conceição. Vozes-Mulheres. Poemas de recordação e outros movimentos, p. 10-11 Disponível em: http://www.letras.ufmg.br/literafro/autoras/24textos-das-autoras/923-conceicao-evaristo-vozes-mulheres. Acesso em: 10 maio 2020.

FEFFERMAN, Marisa. Vidas arriscadas: o cotidiano dos jovens trabalhadores do tráfico. Petrópolis: Vozes, 2006.

FERNANDES, Florestan. A revolução burguesa no Brasil: ensaio de interpretação sociológica; prefácio José de Souza Martins. 5. ed. São Paulo: Globo, 2006.

FERREIRA, Ricardo Alexandre. O tronco na enxovia e livres nas prisões paulistas dos oitocentos. In: MAIA, Clarissa Nunes (org). Historia das Prisões no Brasil, vol 1. Rio de Janeiro: Anfiteatro, 2017.

FERRUGEM, Daniela. Guerra às drogas: e a manutenção da hierarquia racial. Belo Horizonte: Letramento, 2019. 
FLAUZINA, Ana Luiza Pinheiro. Corpo negro caído no chão: o sistema penal e o projeto genocida do Estado brasileiro. Rio de Janeiro: Contraponto, 2008.

GARLAND, David. A cultura do controle: crime e ordem social na sociedade contemporânea. Rio de Janeiro: Revan, 2014.

GIORGI, Alessandro De. A miséria governada através do sistema penal. Rio de Janeiro: Revan; ICC, 2013.

GONÇALVES, Renata. Quando a questão racial é o nó da questão socia. R. Katál., Florianópolis, v. 21, n. 3, p. 514-522, set./dez. 2018. ISSN 1982-0259.

GORENDER, Jacob. O escravismo colonial. 6. ed. São Paulo: Expressão Popular; Fundação Perseu Abramo, 2016.

GONZÁLES, Lélia. Racismo e sexismo na cultura brasileira. Revista Ciências Sociais Hoje, São Paulo: ANPOCS, p. 223-244, 1984.

HOBBES de MALMESBURY, Thomas. Leviatã ou Matéria, Forma e Poder de uma Estado Eclesiástico e Civil. Trad. de João Paulo Monteiro e Maria Beatriz Nizza da Silva. São Paulo: Martins Fontes, 2003. Disponível em:

http://www.dhnet.org.br/direitos/anthist/marcos/hdh thomas hobbes leviatan.pdf.

Acesso em: 10 maio 2020.

JAMES, C. L. R. Os jacobinos negros: Toussant L'Ouverture e a revolução de São Domingos. São Paulo: Boitempo, 2010.

JESUS, Carolina Maria de. Quarto de Despejo: diário de uma favelada. 10 ed. São Paulo: Ática, 2014.

LÊNIN, V. I. O Estado e a Revolução: o que ensina o marxismo sobre o Estado e o papel do proletariado na revolução. [tradução revista por Aristiides Lobo] 1. ed. São Paulo: Expressão Popular, 2007.

LOCKE, John. Dois tratados sobre o governo. Trad. Julio Fischer. São Paulo: Martins Fontes, 1998.

LIMA, Rita de Cássia Cavalcante. Uma história das drogas e do seu proibicionismo transnacional: relações Brasil-Estados Unidos e os organismos internacionais. 2009. 365 f. Tese (Doutorado em Serviço Social). Programa de Pós-Graduação em Serviço Social da Universidade Federal do Rio de Janeiro, Rio de Janeiro, 2009.

LOSURDO, Domênico. Contra-história do liberalismo. Aparecida - SP: Ideias e Letras, 2006.

MALAGUTI BATISTA, Vera. O medo na cidade do Rio de Janeiro: dois tempos de uma história. Rio de Janeiro: Revan, 2014.

MARX, Karl. Manuscritos econômicos-filosóficos e outros textos escolhidos.

Argum., Vitória, v. 12, n. 3, p. 10-25, set./dez. 2020. | ISSN 2176-9575 
Seleção de textos: José Arthur Giannotti; Tradução: José Carlos Bruni. 4. ed. São Paulo: Nova Cultural, 1987. (Pensadores).

M’BOKOLO, Elikia. África negra: história e civilizações. Tradução de Casa das Áfricas. São Paulo: Casa das Áfricas, 2008.

MOURA, Clovis. Quilombos: resistência ao escravismo. São Paulo: Ática, 1989.

MUNANGA, Kabengele. Uma abordagem conceitual das Noções de Raça, Racismo, Identidade e Etnia. Palestra proferida. In: SEMINÁRIO NACIONAL RELAÇÕES RACIAIS E EDUCAÇÃO-PENESB-RJ, 3., Rio de Janeiro, 2003. Anais [...]. Rio de Janeiro, 2003.

NASCIMENTO, Abdias. O genocídio do Negro Brasileiro: processo de um racismo mascarado. 3. ed. São Paulo: Perspectivas, 2016.

PASSETTI, Edson. Das fumeries ao narcotráfico. São Paulo: EDUC, 1991

POMPEIA, Raul. Luiz Gama, histórico jurista negro e abolicionista será inscrito na OAB em cerimônia de homenagem. Justificando, 29 out. 2015. Disponível em: http://www.justificando.com/2015/10/29/luiz-gama-historico-jurista-negro-eabolicionista-sera-inscrito-na-oab-em-cerimonia-de-homenagem/. Acesso em: 10 jun. 2020.

PIROLA, Ricardo Figueiredo. A lei de 10 de junho de 1835: justiça, escravidão e pena de morte. 2012. Tese (Doutorado em História)- Programa de PósGraduação em História do Instituto de Filosofia e Ciências Humanas da Universidade Estadual de Campinas, Campinas, 2012.

ROCHA, Andréa Pires. O juvenicídio brasileiro: racismo, guerra às drogas e prisões. Londrina: EDUEL, 2020

ROCHA, Andréa Pires. Relatório Final da Pesquisa "Prisão Provisória de Jovens pelo crime de tráfico de drogas após a realização das Audiências de Custódia em Londrina/PR”. Desenvolvida durante o Estágio de Pós Doutoramento no Programa de Pós Graduação em Serviço Social da ESS-UFRJ, Rio de Janeiro, 2018.

ROCHA, Andréa Pires. Trajetórias de adolescentes apreendidos como "mulas” do transporte de drogas na região da fronteira (Paraná) Brasil - Paraguai: exploração de força de trabalho e criminalização da pobreza. 2012. Tese (Doutorado em Serviço Social) - Universidade Estadual Paulista, Franca, São Paulo, 2012.

RODRIGUES, Thiago M. S. Política e drogas nas Américas. São Paulo: EDUC; FAPESP, 2004.

RUSCHE, Georg; KIRCHHEIMER, Otto. Punição e estrutura social. 2. ed. Rio de Janeiro: Revan, 2004. 
SOMET, Yoporeka. África e Filosofia. Tradução. Revista Sísifo, Feira de Santana, v. 1, n. 1 (2014-) n. 4, nov. 2016.

TRINDADE, José Damião de Lima. Os direitos humanos: para além do capital (Prefácio). In: BRITES, Cristina M.; FORTI, Valeria. (orgs) Direitos Humanos e Serviço Social: polêmicas, debates e embates. Rio de Janeiro: Editora Lumen Juris, 2011.

VALOIS, Luiz Carlos. O Direito Penal da guerra às drogas. 2. ed. 1. reimp. Belo Horizonte: D'placido, 2017.

WACQUANT, Loïc. Punir os pobres: a nova gestão da miséria nos Estados Unidos. Tradução de Sérgio Lamarão. 1. reimp. Rio de Janeiro: Revan, 2013.

WACQUANT, Loïc. As prisões da miséria. Tradução de André Telles. Rio de Janeiro: Jorge Zahar, 2001.

WILLIAMS, Eric. Capitalismo e escravidão. trad. Denise Bottmann; Prefácio Rafael de Bivar Marques. 1. ed. São Paulo: Companhia das Letras, 2012.

\footnotetext{
Andrea Pires ROCHA

Graduação em Serviço Social pela UNESP (200o). Trabalhou como Assistente Social na execução de medidas socioeducativas em meio fechado (FEBEM/SP - 2002) e em meio aberto na Prefeitura Municipal de Maringá (PR), depois com famílias. Mestrado em Educação pela Universidade Estadual de Maringá (UEM ) (2005). Doutorado em Serviço Social pela UNESP (2012) e o "sanduíche" no período de seis meses em Madrid - Espanha, na Universidade Complutense de Madrid, com bolsa CAPES/Fundação Carolina (2011). Fez estágio de Pós Doutorado no Programa de Pós Graduação da Escola de Serviço Social da UFRJ (2018). Desde 2004 é docente da UEL no Departamento de Serviço Social, atuando na graduação e no Programa de Pós-Graduação em Serviço Social e Política Social.
} 